\title{
SABERES, PODERES E ATUAÇÃO DE MULHERES NA ALDEIA INDÍGENA ASSURINÍ DO TROCARÁ, MUNICIPIO DE TUCURUÍ/PA
}

\author{
KNOWLEDGE, POWERS AND PERFORMANCE OF WOMEN IN \\ THE ASSURINI INDIGENOUS VILLAGE OF TROCARÁ, IN THE CITY \\ OF TUCURUÍ, STATE OF PARÁ
}

Bárbara Ribeiro ${ }^{1}$

Benedita Celeste de Moraes Pinto ${ }^{2}$

\begin{abstract}
RESUMO:
Este estudo analisa a atuação de mulheres Assuriní da aldeia indígena Trocará-Tucuruí/PA, nas diferentes esferas que constituem as sociabilidades e os rituais tradicionais dessa etnia. Utilizamos a metodologia da História Oral, a memória e a observação participante, cujas análises evidenciaram que as mulheres Assuriní sempre foram atuantes na funcionalidade dessa aldeia, seja no que se refere aos trabalhos no âmbito doméstico, ou na luta por direitos através de suas atuações nos cargos de lideranças. Assim como, são grandes incentivadoras das práticas tradicionais, buscando, a partir do respeito conquistado entre os moradores, estimular a continuidade cultural, visto que possuem funções primordiais e atuam de maneira efetiva nos processos diversos que desencadeiam os rituais tradicionais.
\end{abstract}

PALAVRAS-CHAVE: Mulher Assuriní; Saberes: Poderes; Protagonismo.

\begin{abstract}
:
This study analyses the performance of Assuriní women of Trocará indigenous village, in the city of Tucuruí, State of Pará, in the different spheres that constitute the sociabilities and traditional rites of that ethnicity. We used the methodology of oral history, memory and participant observation, whose analyses showed that the Assuriní women have always played an active role in this village, both in the scope of household chores and in the fight for rights through their actions in leadership positions. As well as they are great incentive for traditional practices and trying, from the respect earned among the villagers, to stimulate cultural continuity, since they have primordial functions and act effectively in the various processes that trigger the traditional rites.
\end{abstract}

KEYWORDS: Assuriní Woman; Knowledge; Powers; Prominence.

\footnotetext{
${ }^{1}$ Doutoranda em Antropologia no Programa de Pós-graduação em Antropologia (PPGA) da Universidade Federal do Pará. Professora da Secretária municipal de Educação de Cametá. E-mail: barbaracameta@gmail.com ${ }^{2}$ Doutora em História PUC/SP, Professora pesquisadora da Universidade Federal do Pará, lotada no Campus Universitário do Tocantins/Cametá, onde atua na Faculdade de História do Tocantins (FACHTO) e no Programa de Pós-Graduação em Educação e Cultura (PPGEDUC). E-mail: celestepinto @ufpa.br
} 


\section{INTRODUÇÃO}

Este estudo se substancia em uma pesquisa maior ${ }^{3}$, realizada na aldeia indígena Assuriní do Trocará (Terra Indígena Trocará/TIT) localizada no município de Tucuruí, no Pará, que buscou analisar as atuações, saberes e poderes das mulheres Assuriní nos múltiplos lugares que constituem essa coletividade indígena, seja nas sociabilidades, na participação política e/ou nos processos tradicionais.

O povo Assuriní da TI Trocará, é originário da região do Pacajá sudoeste paraense, se estabelecendo na região atual por volta de 1953 após conflitos com os indígenas Parakanã. Nos primeiros anos de contato com a população local, na maioria fazendeiros, camponeses e moradores da zona urbana, ocorreram perdas significativas na sua população, causando uma diminuição considerável, devido epidemias de diarreia e gripe (ANDRADE, 1992, p.16).

Contudo, os Assuriní foram se fortalecendo e atualmente possuem uma estimativa de 700 habitantes vivendo nas extensões da Terra Indígena Trocará, separados em quatro aldeias: a Ororitawa, Oimotawara, Mururitawa e a aldeia Trocará, lócus deste estudo. Essa etnia indígena busca de todas as formas, por meio de engajamento interno e das ações de suas lideranças, conseguir direitos em todos os aspectos de sua vida, como na saúde, educação, infraestrutura, no fortalecimento de seu território e da cultura (RIBEIRO, 2017, p.50).

A pesquisa que desencadeou este trabalho, foi realizada na aldeia Trocará no segundo semestre de 2015 e segundo semestre de 2016, usamos enquanto metodologias a História Oral, mediante entrevistas com homens e mulheres da aldeia, a memória oral e a observação participante, visando analisar as articulações das mulheres Assuriní diante dos direitos conquistados, como estão se organizando enquanto grupo para fortalecimento dos aspectos culturais e como agem diante das mudanças sentidas internamente em diferentes setores dessa aldeia. Conforme defende Thompson (1992, p. 46), a História Oral tem demostrado ser de extrema importância para esse tipo de estudo, por se tratar de uma ferramenta que se baseia na memória dos sujeitos para questionar interpretações deturpadas feitas sobre fatos ou alguns

\footnotetext{
${ }^{3}$ Pesquisa ligada ao Grupo de Pesquisa História, Educação e Linguagens na Região Amazônica-HELHRA$\mathrm{CNPq}$ ), que resultou na dissertação de mestrado "Mahíra e os Saberes Femininos: gênero, educação e religiosidade na comunidade indígena Assuriní do Trocará, município de Tucuruí/PA", defendida em março de 2017, no Programa de Pós-Graduação em Educação e Cultura - PPPGEDUC/UFPA-Cametá, sob orientação da prof $^{\mathrm{a}}$. Dra. ${ }^{\mathrm{a}}$. Benedita Celeste de Moraes Pinto.
} 
povos, assim como é uma metodologia que trabalha pela valorização e reconhecimento das lutas pela igualdade social desses sujeitos.

No mesmo sentido, Portelli (2010, p. 30) afirma que a oralidade e a memória se constituem como uma experiência do aprendizado, marcada por observações recíprocas, por haver uma troca entre as pessoas que estão envolvidas neste processo. Tal questão é de grande importância para que haja melhor compreensão em relação aos significados culturais, políticos e sociais de um grupo, sendo necessário que se leve em consideração as diferenças dos sujeitos e, ao mesmo tempo, crie possibilidades de diálogos para que ocorra trocas entre ambos e assim, seja constituído o aprendizado em relação à experiência do outro, como parte fundamental para as relações sociais diárias.

Por outro lado, Minayo (2013, p. 77) traz a importância da observação participante no desenvolvimento de pesquisa qualitativa, para que o/a pesquisador/a estabeleça uma boa relação com os sujeitos. Assim, para que o trabalho dê certo, é imprescindível que haja interação, diálogo e confiança entre ambos, caso contrário, tanto entrevistador/a, quanto entrevistado/a não conseguirão obter e atingir seus propósitos.

Sem dúvidas, tais metodologias foram essenciais para as pesquisas realizadas entre os Assuriní, uma vez que possibilitaram maior compreensão daquela realidade e dos sujeitos que ali estão inseridos. A partir de maior entendimento dos conjuntos simbólicos que regem suas vivencias e das interações internas, se evidenciou que atualmente dentro da aldeia Trocará, para fortalecimento de suas pautas, lutas por direitos, continuidade de suas práticas culturais e articulação entre os moradores, cargos de lideranças foram criados para que assim, cada núcleo familiar se articule e participe ativamente de todos os processos ali desenvolvidos.

As lideranças são aquelas pessoas que dentro e fora da aldeia estão sempre buscando o bem comum, a continuidade dos saberes e práticas de seu povo, os direitos da coletividade e o melhor para todos/as. As lideranças escolhidas são homens e mulheres que se dedicam no fortalecimento cultural, melhorias estruturais, educacionais e engajamento político em virtude dos desamparos que os Assuriní passaram no decorrer de sua história e que ainda permanecem. Contudo, para além do cargo reconhecido, são consideradas como lideranças aquelas pessoas, que mesmo de forma discreta, contribuem significativamente para a continuidade cultural e fortalecimento de seu povo.

Nesse processo, as mulheres Assuriní compartilham e assumem diferentes funções, seja enquanto atuantes nos movimentos políticos e atos de resistência para conseguir ampliar os direitos necessários nas diferentes esferas sociais que compõem a sociedade Assuriní, ou 
como incentivadoras da continuidade cultural, das práticas tradicionais e do respeito aos seus semelhantes dentro e fora da aldeia.

Vale destacar que dentro das sociabilidades deste povo, as mulheres podem assumir funções de lideranças quando atingem a maturidade, sobretudo, quando estiverem casadas e possuírem filhos, o que inicia por volta dos 14 a 17 anos. Até então, são consideradas crianças e seguem os ensinamentos das mães de acordo com os papéis sociais designados às mulheres, ou seja, estão em constantes aprendizados de atividades vinculadas ao âmbito doméstico, como cuidar da casa, da alimentação, plantação e a confecção dos artesanatos. À medida que crescem e/ou casam passam também a transitar nas esferas públicas, participando das reuniões das lideranças, se envolvendo em projetos que fortaleçam e incentivem a continuidade das práticas tradicionais e nas ações e movimentos de luta por direitos. A dedicação e interesse nestas causas são fatores que contribuem para que sejam vistas enquanto lideranças junto aos moradores e representem seu povo.

Em relação aos cargos de lideranças e das atuações dentro da aldeia Trocará, destacase o protagonismo dessas mulheres e sua importância para a vivência deste povo, visando o seu fortalecimento enquanto população étnica e suas lutas por direitos. As mulheres Assuriní se articulam, são atuantes e buscam somar nas lutas e nas práticas coletivas, conseguindo maior atenção e atuação em diferentes setores da aldeia, refletindo no reconhecimento de muitas delas como lideranças indígenas, já que são engajadas no incentivo e continuidade de práticas tradicionais, na luta ativa por direitos e bem estar de toda a coletividade.

Da mesma forma, as mulheres Assuriní também exercem funções primordiais nas festas, rituais e práticas culturais tradicionais realizadas dentro da aldeia Trocará, participando de maneira efetiva e como responsáveis por sua organização e execução. Caso dessa natureza é observado, sobretudo, na festa do mingau ${ }^{4}$, da qual são as protagonistas, assumindo todas as etapas de realização, se destacando principalmente nas danças e cantorias. Por mais que em outros rituais sua participação tenha algumas restrições como na festa do jacaré, nesta festa elas assumem funções importantes, igualmente aos homens, já que para que tudo saia dentro

\footnotetext{
${ }^{4}$ De acordo com Andrade (p. 91, 1992) a festa do mingau realizada entre os Assuriní está ligada ao ciclo agrícola deste povo, considerando a época de chuva, plantações e colheitas. Nesse ritual são as mulheres que desempenham todas as funções necessárias para sua realização, organizando, tendo destaque nas danças e cantorias, assim como, são elas que se ocupam em preparar e servir o mingau para os demais participantes. Sua efetiva participação não corresponde apenas por ser uma representação das atividades domesticas, mas principalmente por estar ligada as esferas de Mahíra o ser mítico Assuriní. As mulheres são as únicas na terra a intermediar o contato humano com este ser espiritual.
} 
do esperado é necessário que ambos desenvolvam suas funções de maneira conjunta dando suporte um ao outro.

Sobre as atividades cotidianas e de caráter doméstico mudanças significativas aconteceram desde que os Assuriní se estabeleceram na aldeia Trocará até os dias atuais, como no processo de subsistência, em relação ao trabalho nas roças, no serviço doméstico, no cuidado com as crianças, entre outras atividades, nas quais as mulheres além de conseguirem maior participação em algumas tarefas que convencionalmente correspondiam ao âmbito masculino, passaram a compartilhar atividades que eram a elas designadas, tais fatos ocorrem devido as reconfigurações que o sistema cultural Assuriní está inserido seja pelas necessidades de maiores incentivos econômicos ou mesmo devido os novos sentidos que a constituição familiar passa atualmente, como evidenciado no decorrer do trabalho.

\section{SABERES PRODUZIDOS PELAS MULHERES ASSURINÍ NO COTIDIANO DA ALDEIA}

As mulheres Assuriní estão envolvidas em vários processos e setores dentro da aldeia Trocará, atuando em cargos estruturais, como: professoras, agentes de saúde e lideranças locais, e ao mesmo tempo produzem agências nos espaços culturais e cotidianos da aldeia e fora dela. Da mesma forma, que incentivam as práticas culturais e saberes tradicionais, participando dos rituais, confeccionando artefatos usados nos espaços ritualísticos e sociais, se fazem presentes nos processos diversos que regem suas vidas e as vivencias coletivas. Muitas Assuriní, principalmente as mais velhas, buscam seguir os ensinamentos dos sábios, dos guardiões da memória dessa etnia indígena, sem, contudo, deixar de interagir com os diferentes acontecimentos que ocorrem no decorrer dos anos. Estas mulheres sempre desempenharam papéis ativos e importantes entre o seu povo, sejam eles relacionados aos trabalhos desenvolvidos no ambiente doméstico, como a confecção dos artesanatos, a produção dos alimentos e cuidados com as crianças ou os que fazem parte do ambiente social, político e cultural.

Nas narrativas de homens e mulheres entrevistados na pesquisa emergem lembranças de outros tempos, quando viviam quase isolados, sobressaltados e temerosos com a presença de invasores, desenvolviam estratégias nos seus arranjos tradicionais, delegando às mulheres a responsabilidade pelos trabalhos de plantação das roças de mandioca, do colher e carregar os produtos, enquanto os homens cuidavam da derrubada e limpeza da mata. Os Assuriní narram 
que, tanto as mulheres, quanto seus maridos faziam as colheitas nas roças, mas ficava a cargo das mulheres carregar a mandioca até o igarapé, onde ficaria de molho, ou então levar até a casa de farinha, onde seria ralada. A mulher era quem trazia os paneiros (cestos usados na coleta da mandioca) cheios de mandioca nas costas. Tradição que ainda é mantida pelos mais velhos, como se observa na imagem a seguir, que retrata o cacique Puraké Assuriní e sua esposa, Wanda Assuriní, caminhando para a roça, é ela quem leva o paneiro nas costas, na volta será ela também que trará os produtos coletados.

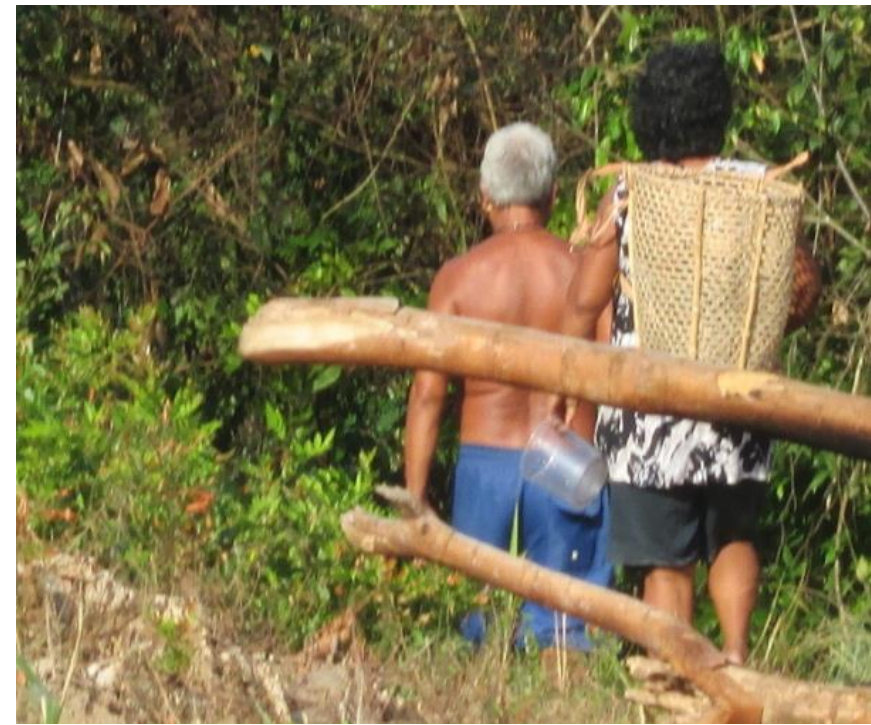

Imagem 1 - Casal Assuriní caminhando para roça: Fonte-RIBEIRO, 2015.

Nas atividades de caça, as mulheres acompanham seus maridos, irmãos ou pais nos períodos que se deslocam para a mata, principalmente, as mais velhas, sendo que sua principal função é carregar a caça depois de abatida, como fica evidente na fala do professor Waremoa Assuriní:

A mamãe né? Que ela carregava peso, muito peso, entendeu. Ela ia pra roça com o papai, tirava a mandioca tudinho, colocava no paneiro, era ela que carregava, entendeu? Caça também quando eles matam, quando eles matavam no mato, ela que tinha esse papel de trazer, carregar, essa era a missão das mulheres e até hoje é assim. Têm uns idosos que ainda eles mantem essa tradição de antes (Waremoa Assuriní, 2015).

A partir da fala de Waremoa Assuriní se observa que são as mulheres que realizam os trabalhos braçais, que necessita de força e agilidade, como o de carregar a mandioca e a caça, costume ainda usual, principalmente entre os Assuriní mais velhos. Como é o caso da senhora Murupy Assuriní, viúva de Nakawaé Assuriní, último pajé desta aldeia, que sempre atuava 
juntamente com o esposo, não apenas nas caçadas, pescarias e colheitas, mas também na realização das festas e rituais tradicionais, assim como, na preparação das músicas e cantorias.

Nossos interlocutores narram que, após a morte de Nakawaé Assuriní em 1992, dona Murupy, que fala muito pouco o português, não interage intensamente dentro da aldeia e prefere seguir os padrões tradicionais do seu povo. Murupy Assuriní caça e pesca na mata da Terra Indígena Trocará, utilizando nestas atividades somente objetos tradicionais, como: o arco e flecha, diferente dos demais indígenas dessa aldeia, que usam espingardas, lanças, entre outros objetos, para obtenção da alimentação. É ela também quem assume todas as funções laborais, para a subsistência de sua família mesmo que estas demandem força e cuidado.

Esses fatores relacionados aos contextos ocidentais e dos padrões socialmente estabelecidos nesses ambientes, estariam classificados como trabalhos atribuídos aos homens pela necessidade do uso de força para sua realização, mas que em diferentes etnias indígenas são desempenhados pelas mulheres devido construções internas e as definições de funções ali estabelecidas, fato que também se designa às atividades domésticas que por elas são desenvolvidas. No entanto, é importante mencionar que em contextos indígenas essas definições acontecem sem conflitos e de acordo com configurações culturais existentes entre cada povo, sem sobreposições de valores.

É o que demonstra Descola (1996, p. 54) em seu trabalho sobre Achuar, evidenciando que as funções realizadas por homens e mulheres entre esse povo não são colocadas como uma superior ou inferior, mas complementares. Os prestígios são conseguidos pelo desempenho perfeito das funções sejam aquelas desenvolvidas pelos homens ou pelas mulheres. As relações são baseadas no respeito, admiração e suporte para que os parceiros sejam vistos com prestígio pelos outros membros, assim, tanto o homem como a mulher oferecem apoio para que seu parceiro tenha sucesso em suas atividades.

Contudo, mesmo se observando que não ocorra disputas no desempenho de atividades ou funções na aldeia Trocará, atualmente, devido interesses internos, muitas atividades foram e continuam sendo modificadas no que diz respeito à divisão de trabalho. Embora, muitas mulheres acompanhem seus maridos na caça, na feitura das roças e na produção da farinha de mandioca, as funções são atribuídas a todos os membros da família. Ainda que as mulheres exerçam maior participação no preparo da caça em suas casas, isso não é mais tarefa exclusiva delas, visto que os homens também desempenham tal função, como mencionado pelo interlocutor Sunitá Assuriní: 
Eu cozinho, em casa todo mundo cozinha, homens, mulheres todo mundo. É as meninas que lavam roupa, tem dias que é a mãe delas que lavam, tem dias que é elas. Se elas não lavar roupa, elas vão fazer outra coisa, por exemplo, encher água, que não tem água na torneira, vai no igarapé encher água, as criançada e as mães delas lavam roupa. Não, eu vou, quando eu vou pro igarapé tomar banho, eu trago um balde de água, dois (Sunitá Assuriní, 2016).

A partir da fala de Sunitá Assuriní, se observa que na maioria das casas há certa divisão de tarefas, por exemplo, as mulheres são as que lavam as roupas e enchem água no igarapé, mas isso não quer dizer que os homens também não realizem tais atividades; a preparação da comida é dividida igualmente entre os membros da casa, e quem puder irá realizá-la, seja homem ou mulher. Em relação a outras tarefas, também, não é algo exclusivo das mulheres, por mais que sejam elas quem mais a realizem, os homens também podem desenvolver. Conforme fala a senhora Joana Assuriní:

É ele [o esposo] que costura aqui em casa, por que eu não sou de costurar não, quando tô com bebê pequeno é ele que cuida, lava meus panos sujo de sangue tudinho, lava roupa, ele faz tudo isso (Dona Joana Assuriní, moradora da aldeia Trocará).

Desta maneira, algumas práticas que eram classificadas culturalmente como funções das mulheres, agora estão passando por processos de transformações e acabam sendo divididas entre os moradores da casa. Assim, é evidente que algumas fronteiras estão se rompendo dentro da aldeia e papéis que antes eram predefinidos estão em negociações, e tanto os homens, quanto as mulheres realizam funções que antes não eram tidas como sua. São os espaços de negociações presentes, não apenas nas sociedades indígenas, mas também em todas as outras.

Tal questão também pode ser observada na imagem 2, em que o senhor Kutiewa realiza algumas dessas atividades de preparo de alimentos. Kutiewa ao vir da caçada, limpou no igarapé a carne da caça que irá cozinhar visando a refeição familiar e, ao mesmo tempo trouxe sua neta que estava aos seus cuidados, após ter aproveitado o tempo que esteve no igarapé para dar banho na criança. Percebe-se, então que na aldeia Trocará os serviços domésticos começam a ser compartilhados pelos sujeitos que compõem o núcleo familiar, independente de sexo, gênero ou papéis estabelecidos. 


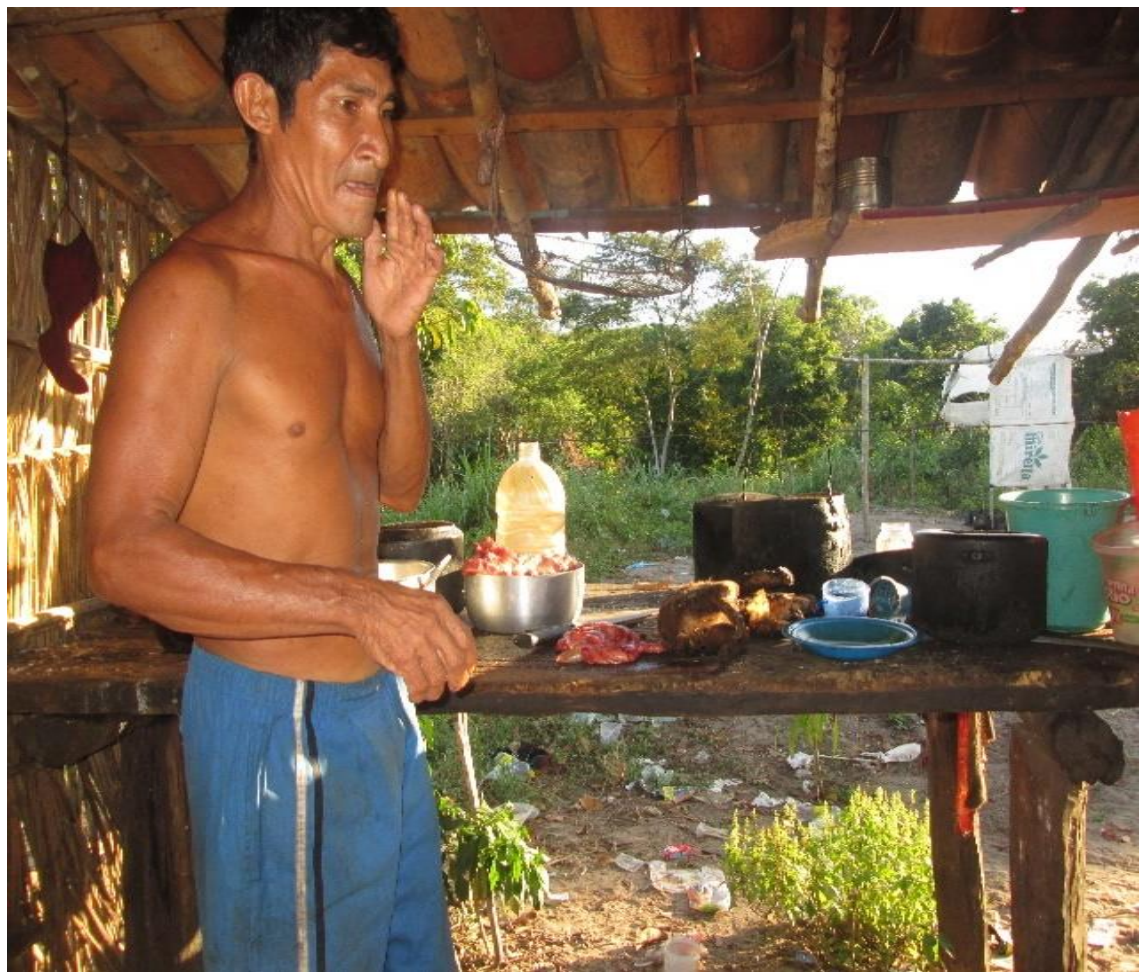

Imagem 2 - Senhor Kutiewa Assuriní preparando a caça. Fonte: RIBEIRO, 2016

As mudanças, relacionadas à divisão do trabalho, também são sentidas no que concerne à preparação das roças de mandioca. No início de formação da aldeia Trocará, os papéis eram todos preestabelecidos. Os homens preparavam a área para plantio: derrubavam, faziam a queima e limpavam, as mulheres plantavam, limpavam as roças e coletavam as raízes. Atualmente, todos os membros familiares estão ligados nesse processo e os trabalhos são compartilhados desde a limpeza do terreno, plantio, cuidado com a roça e colheita.

Para fazer a farinha existem algumas divisões compartilhadas com toda a família: os homens são quem retiram a lenha para preparar o fogo, as crianças tiram a mandioca do igarapé depois de alguns dias "de molho" para amolecer e ajudam a descascá-las, e as mulheres cuidam da massa e da preparação para o forno. Para torrar a farinha, tanto os homens, como as mulheres fazem, sendo assim todos os membros da família, independente de sexo, e faixa etária são encarregados de preparar a farinha para o consumo.

Essas mudanças em relação à participação das mulheres na aldeia Trocará não são apenas no que se refere aos serviços realizados no seio familiar e no ambiente doméstico, mas 
também em torno das questões sociais da aldeia, uma vez que muitas mulheres atuam como lideranças indígenas interagindo juntamente aos homens para conseguir melhorias para a coletividade, ou mesmo atuando dentro da aldeia intermediando ou aconselhando os moradores nas esferas educacionais, políticas e culturais.

De acordo com Canclini (1997, p. 107), essas mudanças culturais são intensificadas, principalmente, a partir das relações e contatos com os diversos espaços, a memória interage com as mutações presenciadas e as formas culturais passam a sofrer um hibridismo no qual não se agrupam mais em grupos fixos e estáticos, mas sim interagindo com as diferenças e os novos processos.

Sendo assim, percebe-se que as mulheres Assuriní estão interagindo com as transformações que vêm ocorrendo em sua aldeia, buscando estratégias e maneiras de serem atuantes a partir das novas configurações sociais que estão inseridas. São professoras, trabalhadoras da saúde, trabalhadoras informais, mães e donas de casa que buscam valorizar seus traços culturais, aconselhar filhos, alunos e manter a coletividade Assuriní em união diante de fatos e situações conflitantes.

As mulheres Assuriní também inspiram respeito dos demais moradores da aldeia Trocará, e com isso buscam incentivar o respeito pelos mais velhos, pelas crianças e por todas as pessoas, pois conhecem a importância do papel de cada um perante a essa sociedade. Para isso, buscam interagir, estar presentes e até mesmo se impor, principalmente, as mais jovens e adolescentes, que expressam seus anseios, lutam pelo que querem e conseguem na maior parte das vezes. Exemplo disso são os casamentos interculturais entre mulheres indígenas e homens não indígenas dentro da aldeia.

De acordo com as tradições Assuriní, esses casamentos eram proibidos, e até nos dias de hoje alguns dizem que não deveriam existir, mas através do contato com os não indígenas e da interação com os contextos urbanos principalmente com os moradores da cidade de Tucuruí, as relações afetivo-sexuais também passaram por mudanças devido os relacionamentos que foram sendo construídos, sobretudo por parte dos homens Assuriní por serem os que mais saiam da aldeia e interagiam na cidade. Essas eram relações proibidas pelos caciques, por isso muitos indígenas saíram da aldeia para morar na cidade com suas companheiras não indígenas, diante disto, as lideranças não tiveram outra alternativa e, para não perder membros da aldeia, aceitaram que trouxessem suas companheiras para morar ali.

Atualmente, é bastante comum os casamentos interétnicos na aldeia Trocará, principalmente, entre homens Assuriní e mulheres não indígenas ou de outras etnias, embora 
ainda ocorra certo receio de aceitação deste tipo de união marital. Uma das principais justificativas para que as mulheres indígenas não pudessem se casar com não indígenas era o fato de existirem mais homens do que mulheres na aldeia, por isso temiam que se elas casassem com não indígenas, poderiam sair da aldeia, havendo uma diminuição populacional.

Contudo, as mulheres Assuriní, passaram a reivindicar tais direitos, na visão delas não era justo que apenas os homens pudessem trazer suas companheiras para a aldeia e elas não, já que também têm direitos. Algumas argumentavam que se não fossem aceitas, sairiam da aldeia para morar na cidade. Por isso, já se observa atualmente mulheres Assuriní casadas com homens não indígenas dentro da aldeia Trocará, mostrando que sabem se impor internamente, reivindicando assim, suas pautas junto às lideranças locais.

Portanto, são nas lutas do dia a dia, e em meio à reuniões que mulheres Assuriní expressam seus desejos, vontades, reivindicações e anseios. Por mais que algumas divisões de atividades internas ocorram, elas não são analisadas como inferiores, enquanto outras são questionadas e entram nas pautas de reivindicações, mostrando os interesses das mulheres para conseguir transitar nos lugares até então não permitidos, como no caso dos casamentos interculturais com não indígenas.

\section{MULHERES ASSURINÍ E LIDERANÇAS INDÍGENAS}

As mulheres Assuriní também estão saindo da aldeia Trocará em buscas de direitos, por isso, passam a desenvolver papéis decisivos nas tomadas de decisão, participando de reuniões, e aquelas que são professoras usam de seus conhecimentos e respeito adquiridos, para conseguir se impor nas reuniões das lideranças colocando seus pontos de vista diante das questões e pautas abordadas e assim participar das diferentes questões que envolvem essa etnia indígena. Daí porque algumas mulheres, ganham repercussão e conquistam o título de lideranças indígenas. As lideranças Assuriní são aquelas pessoas que contribuem efetivamente na luta por direitos, nos movimentos de resistência, que participam e contribuem com as reuniões, e principalmente se preocupam com a coletividade, por isso, ganham papéis de destaques e títulos políticos frente aos demais moradores.

Muitas mulheres Assuriní, que se engajam nas lutas incentivando o conhecimento, a valorização e a transmissão de práticas e saberes culturais são reconhecidas por suas atuações, poderes, saberes e representatividade junto ao seu povo, conforme se observa na narrativa do professor Waremoa Assuriní, 
A escolha de uma outra liderança mulher, aí foi escolhida a professora Paturina e a Iara como representante, que assim, pros eventos que envolvia as mulheres elas estavam presente. Também a professora Paturina, a professora Wanderleia, a Iara, entendeu? (Waremoa Assuriní, 2016).

A partir desta fala de Waremoa Assuriní, verifica-se que mulheres escolhidas para exercer lideranças são sempre aquelas que atuam em prol do coletivo, como incentivadoras das práticas tradicionais, estimulando a continuidade cultural do povo Assuriní, assim como do processo educacional, buscando melhorias para alunos, professores e aos habitantes da aldeia como um todo. Nestas perspectivas, saem da aldeia em busca de informações para melhoria educacional e de garantia de direitos, intencionando extrair o melhor do mundo exterior para que todos possam compartilhar do que foi aprendido e ensinado.

Estas mulheres, ao saírem da aldeia enquanto lideranças, buscam adquirir conhecimentos que possam ser aplicados na vivencia coletiva, da mesma forma, se afirmam enquanto pertencentes a uma população étnica perante os não indígenas, exigindo respeito, expondo e valorizando suas diversas concepções de mundo, e assim o fazem como parte de um povo com cultura e costumes diferentes, ativo que sabe reivindicar direitos por conta própria, sem precisar que outros falem por si, ou que sejam "tutelados".

Segundo Ribeiro (2017, p. 45), as mulheres assumem atualmente grande protagonismo na aldeia Trocará, participando efetivamente de espaços de poder e decisão para conseguir direitos. No mesmo sentido, estão incentivando a continuidade das práticas tradicionais, como os rituais de iniciação, cantorias e danças que compõem os conjuntos simbólicos do sagrado Assuriní.

Essas mulheres buscam continuar a transmissão das práticas culturais, as festas, os rituais tradicionais, a língua materna, fortalecendo seu povo e reafirmando os saberes repassados no decorrer de sua história pelos/as sábios/as. Para isso sempre incentivam a participação de todos/as nos rituais, como a festa do mingau, a festa do jacaré e a dança da tukasa. Por sua participação e presença ativa estão também auxiliando nas danças e cantorias, que se constituem essenciais para a continuidades desses momentos ritualísticos.

Atualmente, muitas mulheres assumem postos de lideranças na aldeia Trocará, neste trabalho destacamos o caso de três delas por suas importantes atuações na referida aldeia. Em relação à valorização cultural, destaca-se a senhora Iara Assuriní, como uma liderança que busca incentivar, principalmente, os mais jovens a participarem das festas, danças, músicas, cantos visando a continuidade de práticas culturais e tradições dos Assuriní. Como é 
observável em uma das narrativas de Iara Assuriní, ao falar dos ensaios que aconteciam na aldeia para os Jogos Mundiais Indígenas de 2015, deixando transparecer seu empenho e atuação para que as mulheres Assuriní fizessem uma boa apresentação na dança da taboka:

Vamo, vamo, mulherada! Mais forte, com gosto. Tá muito fraco, não é assim. No meu tempo quando eu dançava e cantava, não era assim, nós cantava mermo, de verdade. Oh! já erraram de novo, para de vergonha e canta com força (Iara Assuriní, 2015).

Iara Assuriní é uma liderança que age mais no incentivo das tradições. E no momento desse ensaio se apresentava muito mais que uma telespectadora, era uma grande estimuladora, técnica e mestra da cultura, que impulsionava as participantes a se dedicarem na dança e no canto. E para isso, ensinava como deveriam fazer, pedia dedicação e mais entusiasmo para demonstrarem a força de seu povo, não apenas fora da aldeia, mas que a vivacidade dessas práticas pudesse estimular os próprios moradores internamente, levando-os a perceber a importância da cultura Assuriní e a riqueza que esta representa.

E desta forma, além do estímulo rotineiro nos ensaios das danças, cantos e músicas, Iara Assuriní é considerada umas das mulheres sábias do seu povo, que detém os saberes necessários para a preparação e realização dos momentos ritualísticos que ocorrem no ápice das festas. Ela se mostra atuante nos diferentes espaços cotidianos da aldeia, cuida da rotina familiar, sempre preocupada com o bem-estar de seu núcleo de parentesco e da participação destes nas práticas culturais. Com essa visão, se dispõem a cuidar dos netos para que as filhas estejam inseridas nos momentos de ensaios das danças e cantorias.

Pode-se dizer que Iara Assuriní percorre as diferentes esferas sociais, culturais e educacionais, que entrelaçam as vivencias Assuriní, sendo também uma das principais idealizadoras da escola indígena da aldeia, intencionando possibilitar educação escolarizada para crianças e jovens indígenas, sem que para isso tivessem que se deslocar para a cidade de Tucuruí ou localidades próximas. Percebe-se seu engajamento nas pautas coletivas e nas lutas por melhores condições de vida ao seu povo, fato aplicado quando se fala das outras duas mulheres lideranças Assuriní, que assim como Iara, são fundamentais para a continuidade do processo educacional e cultural dentro da aldeia e das lutas por direitos fora dela.

As professoras Wanderleia e Paturina Assuriní, são duas lideranças que inspiram respeito e possuem grande influência dentro da aldeia Trocará. Estas duas mulheres são figuras constantes nas pautas de resistência, nas reivindicações por direitos garantidos fora da 
aldeia e, sobretudo, no processo de ensino-aprendizagem. Participam de eventos e encontros externamente para divulgar as demandas coletivas dos Assuriní, saem em buscam de qualificação para que possam agregar valores e conhecimento dentro da aldeia. Dizem que esse é o compromisso que assumem com os moradores quando receberam o título de lideranças, por isso buscam atuar da melhor forma possível para contribuir com os habitantes da aldeia Trocará.

Pela responsabilidade que demanda, a professora Paturina, mesmo sendo reconhecida como uma liderança Assuriní devido sua atuação efetiva junto aos moradores, afirma ter receio de se afirmar como tal:

\begin{abstract}
Bom eles falam assim né? Que eu poderia ser uma liderança né? Mas ainda não cheguei pra dizer assim que tô preparada pra ser uma liderança, porque pra ser uma liderança tem que ser bem né? Tem que se expressar muito pra conversar, com as mulher, seus serviços, trabalho, educar seus filhos. Então pra ser uma liderança tem que ser isso também, saber organizar as mães, explicar pras crianças, saber ensinar como educar. Eles falam que eu sou uma pessoa que pode ser uma liderança, mas eu ainda não cheguei assim pra ter essa conversa. Eu participo das reuniões, pra mim é importante ser uma liderança, muito importante dentro da comunidade (Paturina Assuriní, 2016).
\end{abstract}

Embora a professora Paturina Assuriní saiba que os demais habitantes da aldeia Trocará a considerem uma liderança importante nesta aldeia, se observa os cuidados por ela demonstrado em se afirmar como uma liderança, devido ao seu entendimento a respeito da importância desta função. Na concepção de Paturina, tal função deve ser exercida com muita responsabilidade e dedicação. Requer compromisso assumido com as famílias, principalmente com as mulheres, as auxiliando, ouvindo e incentivando no cuidado dos seus, dando apoio para que estas possam educar seus filhos seguindo as premissas Assuriní, com base no respeito às pessoas, especialmente aos mais idosos, os sábios da aldeia, seguindo tradições e práticas culturais.

Paturina Assuriní desenvolve estratégias de incentivo e apoio aos estudantes, procurando maneiras para que dentro do contexto escolar as crianças entendam e respeitem as diferenças, se respeitem e reconheçam que fazem parte de um povo diferenciado, com valores próprios, e com raízes fincadas nos saberes encentrais. Por isso, esses saberes devem ser continuados e fortalecidos através da afirmação de cada um, enquanto Assuriní, respeitando suas diversidades e lutando pelo bem coletivo dentro e fora da aldeia. 
Esta líder Assuriní também é reconhecida como uma das mulheres de “dons” que ampara as mulheres durante todo o processo de gravidez. Por mais que a maioria dos partos das mulheres Assuriní não aconteçam mais na aldeia, já que as mulheres em trabalho de parto são encaminhadas para um hospital na cidade de Tucuruí, Paturina conta que aprendeu o ofício de partejar com uma tia, por isso se dispõe a auxiliar as mulheres, indicando as ervas e raízes para cada fase gestacional, visando possibilitar alívios e confortos nesse momento tão importante de suas vidas. Contudo, Paturina afirma que se necessário for, está apita em auxiliar diretamente no parto das mulheres (RIBEIRO, 2020, p.92). Esses fatores expressam sua dedicação e engajamento com a população, ao mesmo tempo expõe o porquê dela receber a função de liderança indígena na aldeia Trocará.

Wanderleia Assuriní é outra liderança que vem lutando de maneira atuante em prol do seu povo. Na condição de professora na escola indígena Wararaawa Assuriní, na aldeia Trocará, busca incentivar crianças e jovens na valorização da cultura, no respeito aos mais velhos e nos aprendizados das danças, cantos e rituais tradicionais. Tem grande preocupação com as famílias, por isso, acompanha as rotinas familiares, buscando informações sobre o que precisam e como pode amparar essas famílias diante de suas necessidades. Assim como, procura conversar com os pais e mães para que se atentem aos filhos, incentivem sua participação nas aulas e os aconselhem sobre a importância da educação escolarizada para que se qualifiquem profissionalmente, sem, contudo, esquecer os saberes ancestrais dos Assuriní.

Wanderleia também é uma mulher atuante na luta dos Assuriní em busca de melhores condições de vida e respeito à diversidade. Para isso, sempre participa de movimentos e eventos para evidenciar a cultura de seu povo, possibilitar conhecimento de suas pautas e mostrar que os Assuriní vêm resistindo no decorrer da história, se fortalecendo diante dos muitos desafios que já passaram no passado e no presente. Nos momentos de reivindicações de suas demandas frente aos órgãos governamentais em diferentes esferas, municipal, estadual ou federal, Wanderleia é uma apoiadora e participante desses movimentos, procurando somar com a coletividade em busca de direitos básicos nas diferentes áreas como na saúde, educação, no respeito ao território e na valorização dos aspectos culturais de seu povo.

A atuação dessas mulheres como lideranças dentro da aldeia Trocará evidencia o quanto as Assuriní estão inseridas e relacionadas nos diversos setores desta população indígena, contribuindo para a continuidade de suas tradições e para obtenção de direitos. Pelo engajamento que demostram e pela contribuição significativamente que exercem nas sociabilidades e tradições, as demais lideranças as reconhecem enquanto primordiais para a 
funcionalidade Assuriní refletindo na intenção de abrir espaços para que outras mulheres se destaquem e assumam tais funções, como expresso na fala do professor Pirá Assuriní:

\begin{abstract}
A gente tem que envolver as mulher também, que eu acho que a ideia da mulher é muito importante né? Por que eu acho que toda reunião que a gente faz é só nós liderança que tamo ali né? $\mathrm{E}$ as mulher, eu acho que ela tá afastada, né? Em toda reunião eu coloco isso pra comunidade, eu acho que a gente tem que envolver a mulher né? Eu acho que ela tem um pensamento melhor do que da gente né? Elas pode criar uma associação pra elas por que elas são capaz, né? Se elas não fossem capaz, elas não tinha hoje presidente lá, então é por isso que sempre falo pro pessoal na reunião, que é muito importante a participação da mulher (Pirá Assuriní, 2015).
\end{abstract}

Observa-se, portanto, quão importante são as mulheres Assuriní dentro da aldeia Trocará, sendo fundamentais para todos os processos desenvolvidos por esse povo, como, em relação às questões tradicionais e as ações sociais de lutas e reinvindicações por direitos e melhorias na funcionalidade da aldeia como um todo. Muitos acreditam que, na maior parte das vezes, elas se silenciam, devido algumas formas de limitação em se expressar, mas que vem ganhando autonomia, conseguindo pontuar suas pautas e suas opiniões. Indicando também nesse sentido, que dentro da aldeia, as construções e reconstruções de gênero estão sendo trabalhadas conjuntamente entre homens e mulheres em prol de melhorias e direitos para seu povo.

\title{
PARTICIPAÇÃO DAS MULHERES NAS FESTAS E RITUAIS ASSURINÍ
}

As crenças, ritos, danças e músicas, são os principais elementos que marcam os rituais tradicionais Assuriní. São nesses momentos que os mais velhos também transmitem os saberes impressos nesses rituais para os mais jovens, para que assim mantenham suas tradições, valores e práticas culturais através de suas participações nos rituais como: a festa do jacaré, a festa do mingau, a dança da taboka e a tukasa. Por mais que as mulheres enfrentem restrições na participação direta em alguns rituais dessas festas, devido a transitoriedade de karowaras que são espíritos de animais, que se fazem presente durante sua realização, percebe-se que desempenham funções primordiais no decorrer de algumas delas.

A restrição de participação das mulheres ocorre em vista que os karowaras se manifestam nos corpos dos homens que desempenham centralidade nos momentos rituais. Esses espíritos se alimentam de sangue de animais e em algumas situações podem não diferenciar humanos de suas presas, devido as mulheres emitirem cheiro de sangue por conta 
do ciclo menstrual podem sofrer ataques dos homens possuídos por karowaras durante os momentos ritualísticos.

Entre os rituais que ocorrem restrições na participação da mulher destaca-se os $\mathrm{d} a$ festa do jacaré, da dança da taboka e da tukasa. A festa do jacaré é um dos rituais mais complexos desse povo indígena por envolver uma serie de significados tradicionais e que transitam as esferas dos segredos do povo Assuriní. Para que aconteça, vários fatores devem ser levados em consideração: a aldeia deve estar em harmonia, o período de captura do animal deve também ser considerada, por isso é indicado que a festa aconteça no período do verão amazônico quando é mais fácil encontrar os jacarés na lagoa. Quando capturado os homens devem levar o animal vivo até a aldeia, dançar com eles nas costas para posteriormente matar, cozinhar e dividir com os participantes do ritual.

Durante os rituais dessa festa as mulheres não devem transitar na frente do jacaré ou dos homens dançando, pois representa muito perigo para elas. Os Assuriní dizem que devido elas emitirem o odor de sangue, que emana do ciclo menstrual, podem despertar os ataques dos karowaras, que agem nos corpos dos homens, e por isso correm riscos até mesmo de vida.

Os cuidados com os karowaras acontecem da mesma forma na dança da tukasa, onde a participação direta da mulher também é restringida. Esse é um dos rituais de preparação do indígena a se tornar pajé e está diretamente relacionada às esferas dos homens, por serem eles os únicos que podem chegar a sawara, o espírito onça. Tal espírito é quem conduz os aprendizados para que atinjam a pajelança. Na dança da taboka são os homens que tocam as tabokas- três flautas de bambu-, enquanto as mulheres cantam e dançam atrás deles. Atualmente, as lideranças Assuriní buscam abrir lugares para as mulheres participarem enquanto tocadoras das tabokas, objetivando participação mais efetivas destas nos rituais desta dança. Por isso, visam ensiná-las a tocar as tabokas, conforme narra o senhor Toriaiwa Assuriní:

Taboka é só os homens que tocam taboka né, então, é ainda hoje né é só o homem. A gente tá tentando também ensinar isso pras mulheres, então é a pessoa que toca taboka é como sempre falei pro papai né conversava isso e falava assim que taboka não é pra qualquer um eu já tentei tocar taboka desde criança né então eu não aprendi a tocar sei tocar um pouco pequeno mais nunca cheguei assim a ter o domínio da taboka. (Toriaiwa Assuriní, 2016). 
Fatores que refletem que entre os Assuriní, apesar dos vários desafios e mesmo formas de limitações, buscam fazer com que as mulheres possam realizar atividades nos rituais e nas festas, que antes eram destinados só aos homens. Embora, a tekatawa, casa de preparação dos rituais, onde o pajé medita no decorrer dos preparativos das festas, ainda seja um espaço exclusivamente masculino, no que concerne um ato de reunião ou celebração. Os homens ficam dentro da tekatawa sentados conversando, enquanto as mulheres ficam do lado de fora em pé, somente depois que os homens saem é que elas e crianças podem se sentar dentro da tekatawa. Segundo narram os Assuriní, algumas mulheres já se sentam juntamente aos homens dentro da tekatawa, mas ainda é minoria. Em tempos passados, em período rituais, ao lado da tekatawa era feito um espaço para que só as mulheres se acomodassem com seus filhos, demarcando a tekatawa como um lugar masculino, que atualmente já começa a ser transitado também pelas mulheres.

Se analisarmos com atenção os diferentes processos que envolvem os rituais tradicionais Assuriní, mesmo que a princípio se observe como lugares de separação dos gêneros e com maior participação dos homens, tanto os homens, como as mulheres desempenham funções igualmente importantes. Embora as mulheres não tenham participação efetiva em alguns rituais, como os que ocorrem na tekatawa, contribuem em outros aspectos igualmente importantes como as danças e cantorias, se constituindo como parte ativa dos rituais, como é possível ser verificado na narrativa a seguir:

Os homens tiram música pra apresentação elas ficam ensaiando junto com os homens esse é o papel delas de cantar a música e de dançar. Os homens eles cantam, mas cantam diferente delas né é o ritmo menos acelerado, elas não elas gritam bem alto mesmo. Tradição Assuriní mesmo, entendeu? a cultura Assuriní tradicional mesmo é: os homens dançam e as mulheres cantam. (Waremoa Assuriní, 2016).

Diante do exposto e das diferentes funções que desempenham é necessário pontuar que as mulheres Assuriní participam diretamente dos rituais tradicionais e se fazem importantes para sua realização. Na festa do mingau, por exemplo, são elas que assumem protagonismo, desenvolvendo todos os procedimentos do ritual. Coletam os frutos na mata, usando principalmente o inajá, preparam o mingau e distribuem entre os participantes. E, enquanto acontece a festa elas também cantam e dançam demarcando sua importância e dos saberes que compartilham nesse momento.

Além deste ritual está ligado a produção agrícola do povo Assuriní, também representa a fertilidade, produtividade e saberes das mulheres dentro do coletivo, assim como, a relação das mulheres com Mahíra, o ser mítico Assuriní. Mahira é o criador Assuriní, quem os 
ensinou todas as técnicas agrícolas, músicas e a confeccionar as flautas tocadas na dança da taboka. As mulheres são as únicas que conseguem se relacionar com Mahira por meio dos sonhos, sendo elas a ligação dos humanos com esse ser mítico. Tal fator demarca sua representatividade simbólica não apenas nos rituais, mas também nas interações e relações cotidianas junto aos demais habitantes (ANDRADE, 1992, p. 118).

A partir dos pressupostos, podemos analisar que as mulheres Assuriní ocupam lugares fundamentais na constituição simbólica e ritualista da aldeia Trocará, desempenhando diferentes papéis nas danças, cantos, músicas e na centralidade ritualística, como ocorre na festa do mingau. Demonstrando o engajamento das Assuriní na continuidade das tradições e na valorização dos ritos, credos e simbologias dessa etnia indígena. As mulheres Assuriní também executam outras funções, que transitam para além das esferas ritualísticas, uma vez que fazem parte da preparação do indígena em pajé, os auxiliando nos momentos dos sonhos e nas criações das músicas, como se observa na narrativa do cacique Puraké Assuriní:

\begin{abstract}
A gente sonha cantando e quando a gente tem mulher, ela escuta a gente cantar sonhando, ela canta também. Aí quando ele acaba de cantar a mulher dele atua mais que ele. Quando ele acorda, eles cantam junto com a mulher. Aí leva pra Tekatawa a música, é aquela música ele vai dançar (Puraké Assuriní, 2015).
\end{abstract}

Verifica-se que a mulher desempenha um importante papel para formação do pajé, pois é através dos sonhos que os homens transitam pelo caminho até sawara, que lhe dará suporte necessário para conseguir receber os karowaras, que lhes auxiliarão nas práticas de curas. É por meio dos sonhos que os dons de pajé são desenvolvidos, manifestando diversas reações como: sorrisos, choros e cantorias. Durante o sonho, quando o homem canta, sua esposa o acompanha, memorizando a música cantada, ao acordar devem cantar a música juntos e depois levar até a tekatawa, onde deve dançar e cantar, dando prosseguimentos aos rituais que o tornará pajé.

Depois que um indígena se torna pajé, sua mulher tem igual responsabilidade, acompanhando, realizando funções na tekatawa e lhe dando assistência nas realizações de curas e nas festas. De acordo com Andrade (1992, p. 132), as esposas dos pajés têm posições diferenciadas no que diz respeito ao sobrenatural indígena, por auxiliarem seus esposos nas atividades desempenhadas por eles, essas mulheres acabam alcançando status de quase pajés e prestígios semelhantes a eles entre os Assuriní. 
Tais fatores expressam as agências das mulheres Assuriní na vida ritual deste povo indígena, assumindo funções primordiais em suas realizações, continuidades e ritualizações. As mulheres, assim como, os homens são partes importantes no contexto ritual, por mais que em alguns deles, elas não possam atuar diretamente por causa dos karowaras presentes, mas participam na sua realização por meio de suas danças e cantorias, da mesma forma, assumem protagonismo em outras, assumindo todas as responsabilidades e centralidade, como ocorre na festa do mingau.

\section{CONSIDERAÇÕES FINAIS}

Diante do que foi exposto no decorrer do presente estudo, visando analisar a atuação de mulheres indígenas da aldeia Assuriní do Trocará nas diferentes esferas que constituem as sociabilidades e os rituais tradicionais dessa etnia, observamos que dentro deste coletivo, não se preocupam em pontuar ou definir as realizações das atividades presentes no seu cotidiano, realizadas por homens e mulheres como desiguais ou uma mais importante que a outra, pois cada um desempenha funções que se constituem fundamentais para a funcionalidade da aldeia. No entanto, não se pode negar as agências de mulheres e sua participação em atividades que até certo tempo na historiografia eram classificadas como apenas função masculina, como as relações de afinidade, realização de atividades que exercem força, agilidade e suas atuações nos espaços públicos e rituais.

As mulheres Assuriní, desde a formação da aldeia Trocará, assumem funções essenciais para as funcionalidades sociais, políticas, rituais e tradicionais deste povo, através de suas atuações nos diferentes espaços de convivência e de ritualizações. Nos momentos de colheita eram elas que carregavam as raízes de mandioca para fabricação de farinha, assim como, carregavam as caças, que eram abatidas pelos maridos na mata, sendo, portanto, responsáveis por atividades que demandam agilidade e força. No decorrer de sua história, para além das atividades domésticas que compõem as funções que assumem, conseguem, a partir das mudanças estruturais, realizar funções e transitar lugares, conseguindo direitos que antes apenas os homens tinham, como ocorre no caso dos casamentos interculturais com não indígenas, assim como, a ocupação do cargo de liderança entre os Assuriní

Esse status de liderança é atribuído àquelas que estão cotidianamente empenhadas tanto na funcionalidade da aldeia, quanto na continuidade das práticas culturais, das festas, dos rituais, da língua materna e dos saberes desse povo. A liderança das mulheres Assuriní 
também está estreitamente ligada as suas atuações nas lutas e consolidação dos direitos em prol da melhoria social, educacional, além da garantia do território do seu povo. No mesmo sentido, participam de eventos, reuniões e movimentos que discutem a respeito da necessidade de valorização cultural e do respeito às suas tradições, atuando diretamente nas reivindicações, manifestações e na busca por qualificação profissional para que possam subsidiar de maneira ativa a população da aldeia.

Nas festas e rituais as Assuriní desempenham importantes papéis, atuando efetivamente para sua realização e nos acontecimentos simbólicos que cada um carrega. As mulheres em consonância com os homens, dão vivacidade aos ritos, símbolos e atos contidos nos rituais. As cantorias, danças e músicas que acontecem na realização dessas festas e rituais são os elementos primordiais para que estes aconteçam e se conectem as esferas sociais e sobrenaturais, possibilitando contato com os seres espirituais indígenas. Conforme, acontece na festa do mingau, cuja participação feminina estabelece a interação dos Assuriní com o ser mítico Mahíra, entidade que atua para a harmonização e resistência desse povo indígena. Tais fatos, expressam o quanto as mulheres indígenas Assuriní são representativas e possuem papéis sociais, culturais, políticos e rituais bem definidos e consolidados dentro da aldeia Trocará, representando a potência, força, saberes e importância que as mulheres exercem dentro desta coletividade.

\section{AGRADECIMENTOS.}

Abrimos espaço neste trabalho para externarmos nossos agradecimentos ao povo Assuriní da Terra Indígena Trocará, pela parceria, amizade e disponibilidade em contribuir e dividir suas histórias, memórias e saberes para composição de nosso trabalho. Um trabalho coletivo, que busca reforçar a importância e evidenciar o protagonismo dos povos indígenas da região Amazônica, sobretudo, do povo Assuriní.

\section{REFERÊNCIAS BIBLIOGRÁFICAS:}

ANDRADE, L. M. M. O corpo e o cosmos: relações de gênero e o sobrenatural entre os Asuriní do Tocantins. 1992. Dissertação (Mestrado em Antropologia) - USP, 1992. 
CANCLINI, N. G. Culturas Híbridas: estratégias para entrar e sair da modernidade. São Paulo: EDUSP, 1997.

DESCOLA, Philipe. The Genres of Gender: Local Models and Global Paradigms in the Comparison of 6 Amazonia and Melanesia. In: GREGOR, T., TUZION, D. (Eds.) Gender in Amazonia and Melanesia. Na Exploration of the Comparative Method. Berkeley: University of California Press, 1996. P. 91-116.

MINAYO, M.C.S. Pesquisa Social: teoria, método e criatividade. 33. Ed. Petrópolis, RJ: Vozes, 2013.

PORTELLI, A. Ensaios de história oral. São Paulo: Letra e Voz, 2010. (Col. Ideias).

RIBEIRO, Bárbara de Nazaré Pantoja. "Mahíra e os saberes femininos: gênero, educação e religiosidade na comunidade indígena Assuriní do Trocará". Dissertação de mestrado apresentada ao programa de pós-graduação em educação e cultura (PPGEDUC) UFPA/Cametá-Pará, 2017.

“Corpo e pessoa Assuriní: práticas de resguardo na aldeia Trocará”. Revista Wamon, v. 5 n. 1.2020 , p. 89-102.

THOMPSON, P. A voz do passado: história oral. Rio de Janeiro: Paz e Terra, 1992.

Artigo recebido em: fevereiro/2021

Artigo aceito em: julho/2021 